\title{
Optimal value of filling pressure in the right side of the heart in acute right ventricular infarction
}

Sali Berisha, Adnan Kastrati, Artan Goda, Ylli Popa

\begin{abstract}
Haemodynamic monitoring was performed within the first 48 hours after the onset of symptoms in basal conditions, during volume loading, and during infusion of glyceryl trinitrate in 41 patients who fulfilled the diagnostic electrocardiographic and haemodynamic criteria of right ventricular infarction. In most patients an increase of mean right atrial pressure up to $10-14 \mathrm{~mm} \mathrm{Hg}$ was followed by an increase in right ventricular stroke work index. But raising the mean right atrial pressure above $14 \mathrm{~mm} \mathrm{Hg}$ was almost always accompanied by a reduction in right ventricular stroke work index. When the mean right atrial pressure was reduced by intravenous glyceryl trinitrate to $<14 \mathrm{~mm} \mathrm{Hg}$ the right ventricular stroke index increased. The same response was seen with cardiac and stroke index. The mean (SD) values of optimal right atrial and pulmonary capillary pressures were $11.7(2 \cdot 1)$ and $16.5(2 \cdot 7) \mathrm{mm} \mathrm{Hg}$ respectively.

Thus cardiac and stroke index increased and the right ventricle reached its maximum stroke work index when the filling pressure was $10-14 \mathrm{~mm} \mathrm{Hg}$. These values may be regarded as the optimal level of right ventricular filling pressure in patients with right ventricular infarction.
\end{abstract}

The ventricular filling pressure in patients with acute myocardial infarction has been the subject of a series of haemodynamic studies. ${ }^{1-3}$ The optimal value of left ventricular filling pressure during acute myocardial infarction has been known for many years. Studies on optimal filling pressure of the right ventricle in patients with right ventricular infarction are, however, few and not conclusive. ${ }^{34}$ In fact, in one of them the true incidence of right ventricular infarction in the patients who were studied was not known. ${ }^{3}$ Others have studied only one subgroup of patients with right ventricular infarction and a cardiac index of $<$ $2 \cdot 21 / \mathrm{min} / \mathrm{m}^{2}{ }^{4}$ whereas the range of values in this syndrome is wide.

This study was designed to establish the optimal value of right ventricular filling pressure in patients with right ventricular infarction.

Patients and methods

Forty one (36 men and five women, mean
(SD) age $56 \cdot 3(7 \cdot 4))$ of the 106 patients admitted to the coronary care unit between February 1986 and March 1988 with a first acute inferior or posteroinferior myocardial infarction fulfilled the diagnostic electrocardiographic and haemodynamic criteria of right ventricular infarction and were the subject of this study. The diagnosis of inferior myocardial infarction was established by the presence of: ( $a$ ) a positive clinical history; $(b)$ a diagnostic increase in serum enzymes and $(c)$ abnormal $Q$ waves in leads II, III, and aVF.

The diagnosis of right ventricular infarction was established by the presence of the following electrocardiographic and haemodynamic findings: (a) ST segment elevation $\geqslant 1 \mathrm{~mm}$ in leads V3R-V4R or (b) QS or QR waves or both in the same leads; $(c)$ mean right atrial pressure $>10 \mathrm{~mm} \mathrm{Hg}$ and greater than, equal to, or not more than $5 \mathrm{~mm} \mathrm{Hg}$ lower than pulmonary capillary pressure (in basal conditions or after volume loading). We chose these criteria because they have a diagnostic specificity of $95-100 \%$ and a high sensitivity. ${ }^{5-7}$ We excluded from the study all the patients with a difference of $>5 \mathrm{~mm} \mathrm{Hg}$ between pulmonary capillary pressure and pulmonary artery diastolic pressure; those with previous myocardial infarction or other diseases such as valvar heart disease, percarditis, pulmonary embolism, left to right shunt, chronic heart failure, and renal insufficiency; and all the patients with a pulmonary capillary pressure $>20 \mathrm{~mm} \mathrm{Hg}$.

HAEMODYNAMIC VARIABLES

After informed consent was obtained from the patient a Swan-Ganz thermodilution catheter was placed in the pulmonary artery within the first 48 hours after the onset of symptoms. Right atrial, right ventricular, and pulmonary artery pressures were recorded with a Bentley Trantec Model 800 transducer on a CGR 1000 apparatus. Cardiac output was determined by thermodilution by an Edwards $9520 \mathrm{~A}$ computer and the average value of three measurements showing a difference of $<10 \%$ was calculated. Heart rate was derived from the electrocardiographic recordings. Arterial pressure was measured with a sphygmomanometer. The haemodynamic indices were calculated according to the following formulas: $\mathrm{CI}=\mathrm{CO} / \mathrm{BSA}$ (where $\mathrm{CI}$ is cardiac index in $1 / \mathrm{min} / \mathrm{m}^{2}, \mathrm{CO}$ is cardiac output in $1 /$ min, and BSA is body surface area in $\mathrm{m}^{2}$ ); SI $=\mathrm{CI} / \mathrm{HR} \times 1000$ (where $\mathrm{SI}$ is stroke index in $\mathrm{ml} /$ beat $/ \mathrm{m}^{2}$ and HR is heart rate in beats $/ \mathrm{min}$ ); RVSWI $=$ SI $\times($ MPAP - MRAP $) \times$ 
0.0136 (where RVSWI is right ventricular stroke work index in g.m.m ${ }^{-2}$, MPAP is mean pulmonary artery pressure in $\mathrm{mm} \mathrm{Hg}$, MRAP is mean right atrial pressure in $\mathrm{mm} \mathrm{Hg}$, and 0.0136 is a conversion factor); LVSWI $=$ SI $\times($ MAP - PCP $) \times 0.0136$, where LVSWI is left ventricular stroke work index in g.m. $\mathrm{m}^{-2}, \mathrm{MAP}$ is mean arterial pressure, and PCP is pulmonary capillary pressure in $\mathrm{mm}$ $\mathrm{Hg}) ; \quad \mathrm{SVR}=$ (MAP - MRAP)/ $\mathrm{CO} \times 80$ (where $\mathrm{SVR}$ is systemic vascular resistance in dyn.s.cm ${ }^{-5}$ and 80 is a conversion factor); PVR = (MPAP - PCP)/ $\mathrm{CO} \times 80$ (where PVR is pulmonary vascular resistance).

\section{VOLUME LOADING}

After control measurements were made a rapid intravenous infusion of Dextran was started at a rate of $200 \mathrm{ml} / 5 \mathrm{~min}$ and the pulmonary capillary pressure was monitored so that it did not exceed $24 \mathrm{~mm} \mathrm{Hg}$. The total volume given to each patient varied from 200 to $1200 \mathrm{ml}$ (mean $500 \mathrm{ml}$ ). Measurements of pressure and cardiac output were repeated only when there was a change of $\geqslant 3 \mathrm{~mm} \mathrm{Hg}$ in right atrial pressure. The change between two consecutive values of right atrial pressure was $>5 \mathrm{~mm} \mathrm{Hg}$ in $75 \%$ of patients and it reached a mean of $6.28 \mathrm{~mm} \mathrm{Hg}$ for the group:

We used intravenous glyceryl trinitrate instead of frusemide ${ }^{3}$ to lower the abnormally raised filling pressures. This was because the action of frusemide is not as easily controlled and may be deleterious in patients with inferior myocardial infarction complicated by shock and increased right atrial pressure ${ }^{8}$ and because ventricular function curves can be constructed by reducing ventricular filling pressure with glyceryl trinitrate. ${ }^{9}$ Ventricular function curves were plotted for each patient to relate ventricular filling pressure to stroke work index, stroke index, or cardiac index. We used mean right atrial pressure as the right ventricular filling pressure because it was more stable and more easily measured. ${ }^{10}$

\section{STATISTICAL ANALYSIS}

We used a two tailed $t$ test for paired observations to compare differences between means. $p$ values of $<0.05$ were regarded as statistically significant. All values are expressed as mean (1 SD).

\section{Results}

Figure 1 shows the relation between right ventricular stroke work index and mean right atrial pressure in all patients. In most the increase of mean right atrial pressure up to 10 $14 \mathrm{~mm} \mathrm{Hg}$ was followed by an increase in right ventricular stroke work index. But if the mean right atrial pressure exceeded $14 \mathrm{~mm} \mathrm{Hg}$ right ventricular stroke work index almost always fell. Subsequent reduction of a mean right atrial pressure to $<14 \mathrm{~mm} \mathrm{Hg}$ by intravenous glyceryl trinitrate was followed by an increase in right ventricular stroke work index.

The mean value of optimal right atrial pressure in the group (chosen in each patient as the value of mean right atrial pressure corresponding to the maximum right ventricular stroke work index) was $11 \cdot 7(2 \cdot 1) \mathrm{mm} \mathrm{Hg}$ (fig 2). The mean value of optimal pulmonary capillary pressure (chosen in each patient as the value corresponding to the maximum left ventricular stroke work index) was $16.5(2 \cdot 7) \mathrm{mm} \mathrm{Hg}$ (fig 3). In 16 patients there was a descending left
Figure 1 Relation between right ventricular stroke work index (RVSWI) and mean right atrial pressure (MRAP) in 41 patients with right ventricular infarction. The bars indicate the range of right atrial pressures at which right ventricular stroke work index is highest.

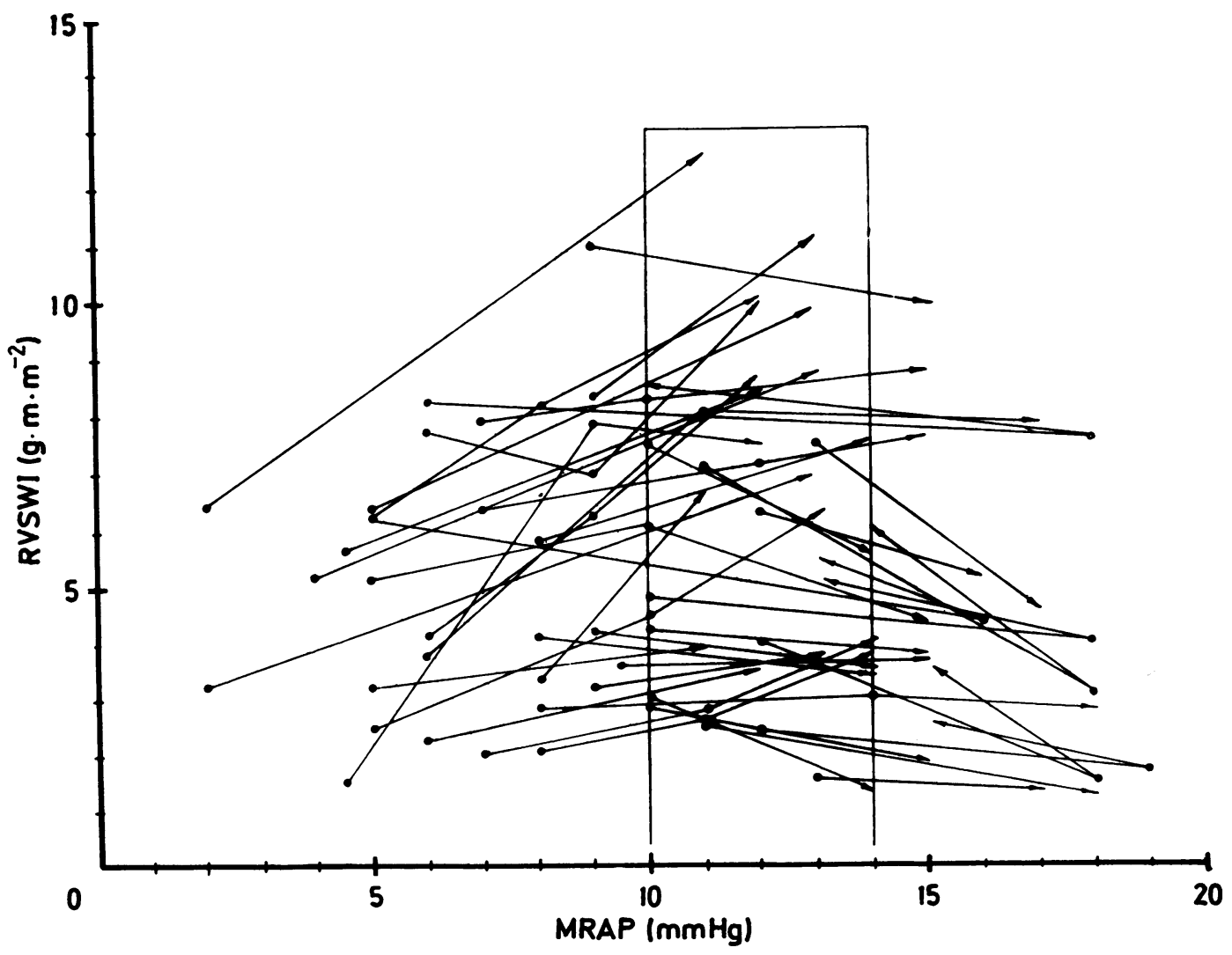




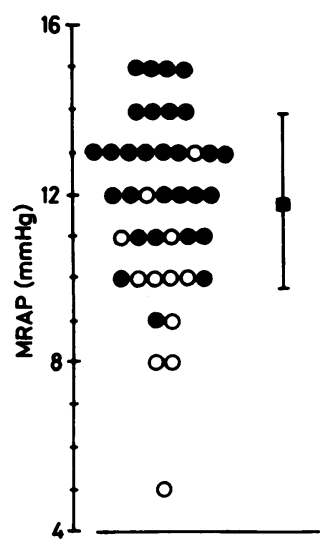

Figure 2 Optimal mean right atrial pressure (MRAP) in 41 patients with right ventricular infarction. Open circles, basal conditions; closed circles, after volume loading. Mean (1SD) is also shown.

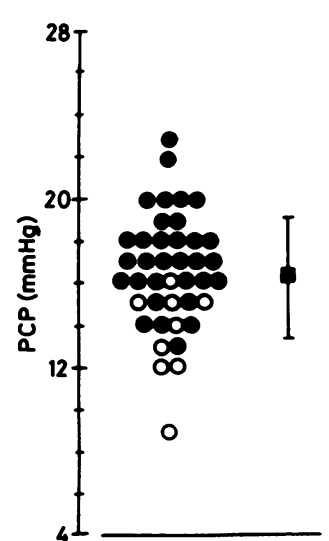

Figure 3 Optimal pulmonary capillary pressure (PCP) in 41 patients with right ventricular infarction. Open circles, basal conditions; closed circles, after volume loading. Mean (1SD) is also shown.

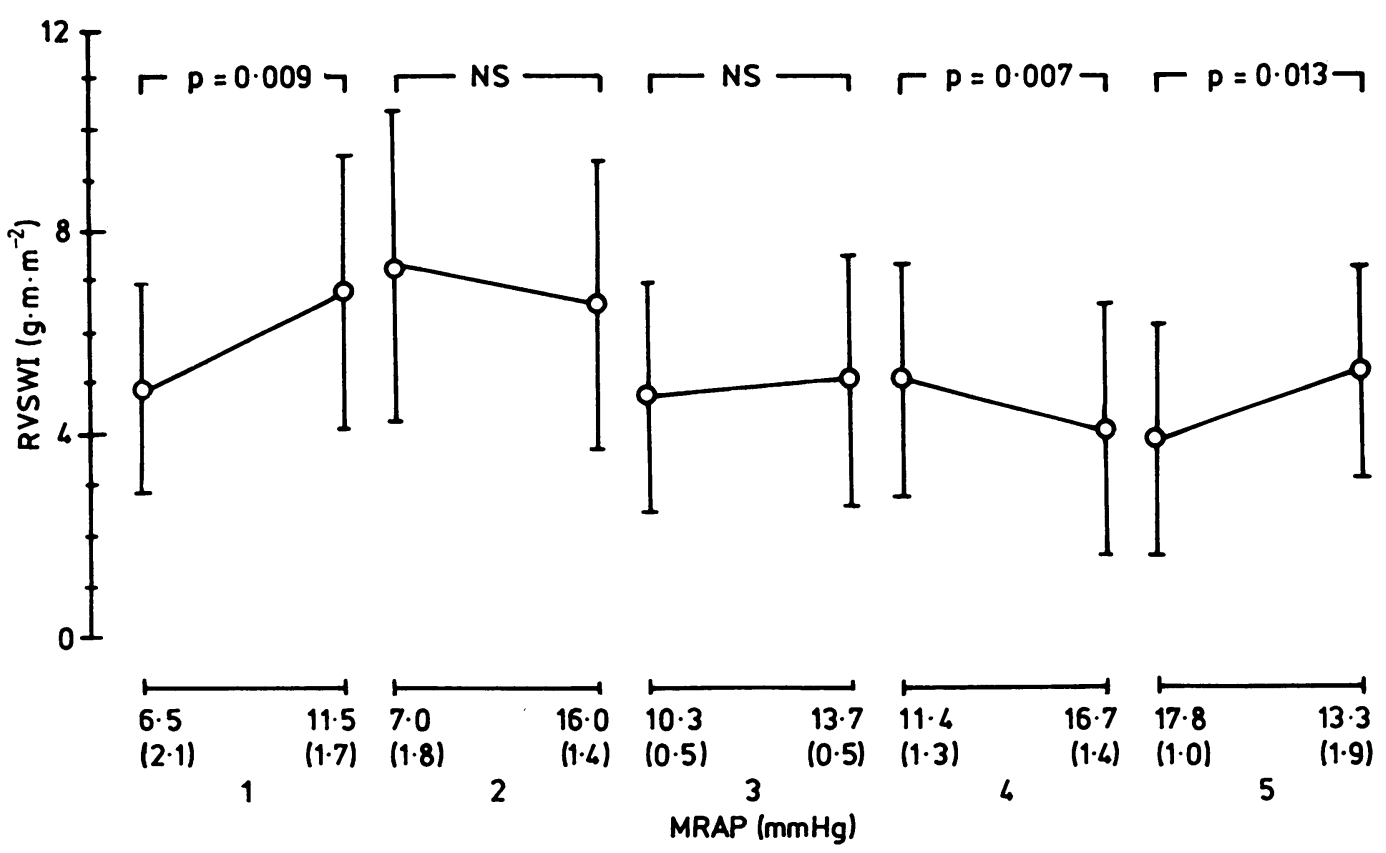

Figure 4 Right ventricular stroke work index (RVSWI) at different mean values of right atrial pressure (MRAP) for subgroups 1 to 5 . See text for explanations. right ventricular one.

To show more clearly that $10-14 \mathrm{~mm} \mathrm{Hg}$ is the optimal value of right atrial pressure, we selected pairs of points representing the relation between right ventricular stroke work index (and stroke index and cardiac index) and mean right atrial pressure that corresponded to two different values of right atrial pressure obtained consecutively by dextran or glyceryl trinitrate infusion. These pairs were divided into five subgroups.

Subgroup 1 included all those pairs in which the first point corresponded to a mean right atrial pressure of $<10 \mathrm{~mm} \mathrm{Hg}$ and the second point to a mean right atrial pressure $\leqslant 14 \mathrm{~mm} \mathrm{Hg}$.

Subgroup 2 contained all those pairs in which the first point corresponded to a mean right ventricular function curve and an ascending atrial pressure $<10 \mathrm{~mm} \mathrm{Hg}$ and the second point to a mean right atrial pressure $>14 \mathrm{~mm} \mathrm{Hg}$.

Subgroup 3 included all those pairs in which both points corresponded to a mean right atrial pressure from 10-14 $\mathrm{mm} \mathrm{Hg}$.

Subgroup 4 included all those pairs in which the first point corresponded to a mean right atrial pressure $\geqslant 10 \mathrm{~mm} \mathrm{Hg}$ and the second point to a mean right atrial pressure $>14 \mathrm{~mm} \mathrm{Hg}$.

Subgroup 5 contained all those pairs in which the first point corresponded to a mean right atrial pressure $>14 \mathrm{~mm} \mathrm{Hg}$ and the second point to a lower mean right atrial pressure obtained by infusion of glyceryl trinitrate.

In subgroup 1 the increase in mean right atrial pressure from $6.5(2 \cdot 1)$ to 11.5 $(1 \cdot 7) \mathrm{mm} \mathrm{Hg}(\mathrm{p}<0.001)$ was accompanied by

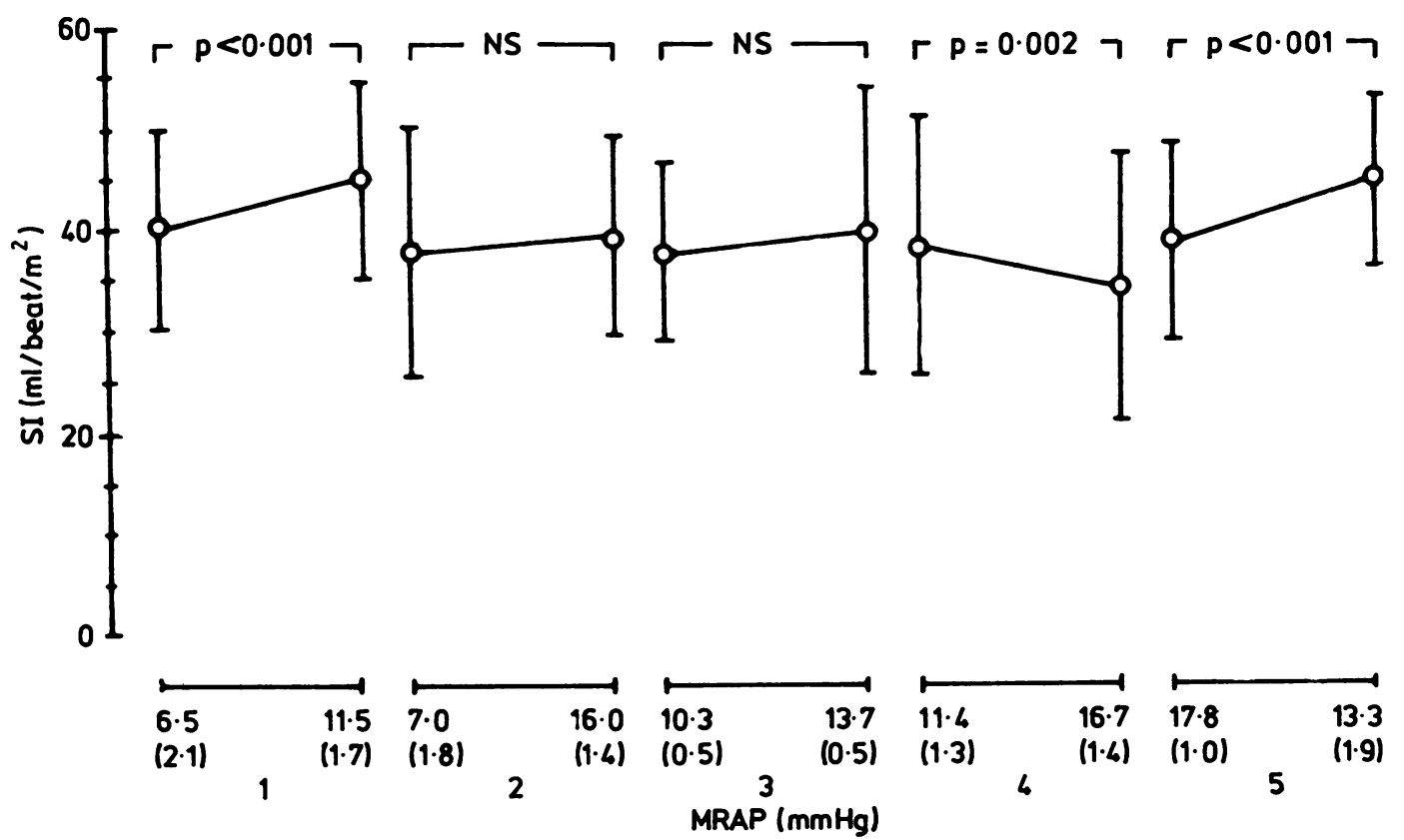

Figure 5 Stroke index (SI) at different mean values of right atrial pressure (MRAP) for subgroups 1 to 5. See text for explanations. 
Figure 6 Cardiac index (CI) at different mean values of right atrial pressure (MRAP), for subgroups 1 to 5 . See text for explanations.

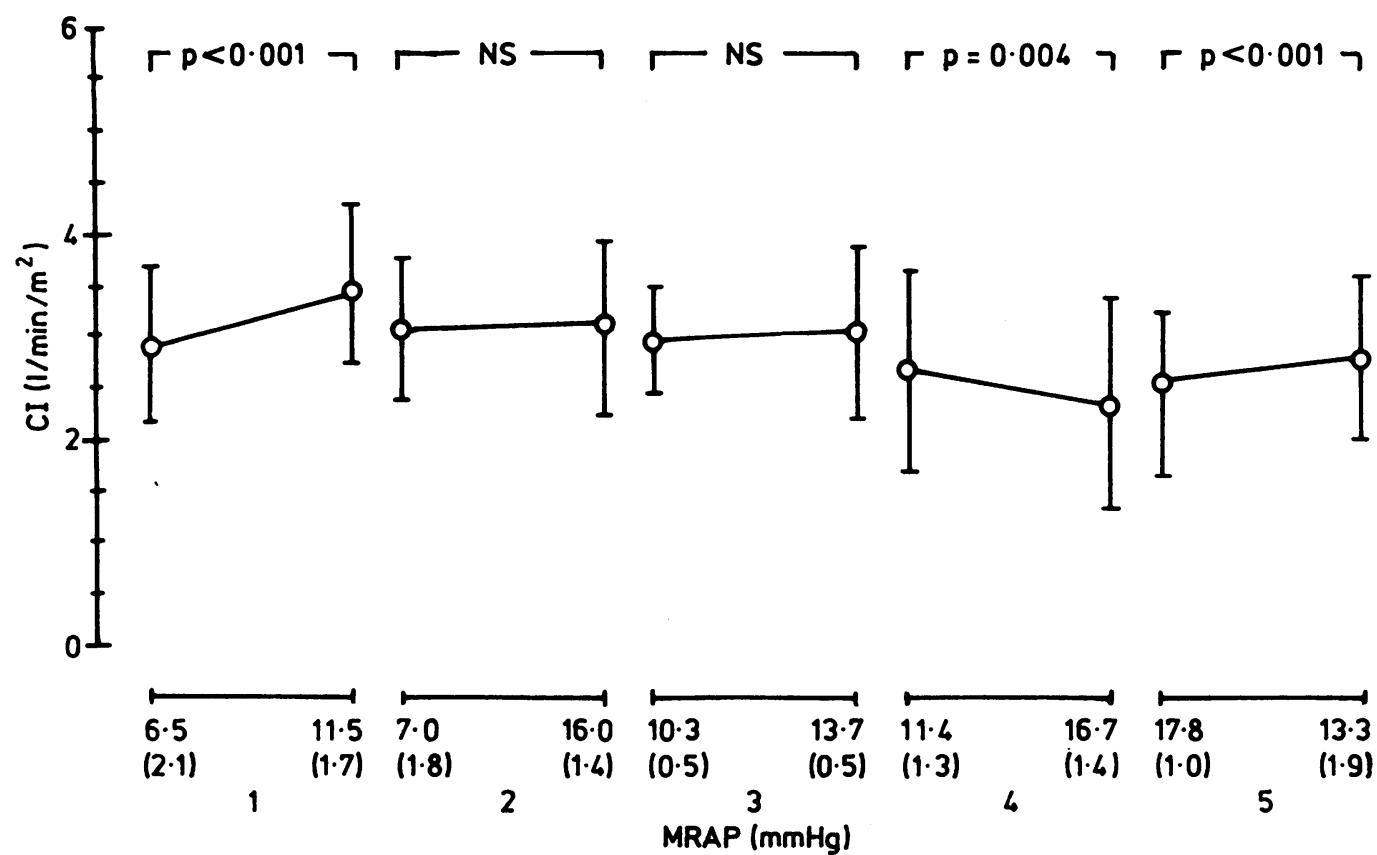

a significant rise in right ventricular stroke work index from $4.9(2 \cdot 1)$ to $6 \cdot 8(2 \cdot 7) \mathrm{g} . \mathrm{m} . \mathrm{m}^{-2}$ $(\mathrm{p}<0.001$, fig 4$)$ and in stroke index from 40.0 $(9.9)$ to $45.2(10.4) \mathrm{ml} /$ beat $/ \mathrm{m}^{2}(\mathrm{p}<0.001$, fig 5).

In subgroup 2 the rise of mean right atrial pressure from $7.0(1.8)$ to $16.0(1.4) \mathrm{mm} \mathrm{Hg}$ $(p=0.009$ ) was followed by an insignificant change of right ventricular stroke work index from $7 \cdot 3(3 \cdot 1)$ to $6 \cdot 5(2 \cdot 9)$ g.m.m ${ }^{-2}$ (fig 4) and of stroke index from $37.9(12.5)$ to $39.5(9.8) \mathrm{ml} /$ beat $/ \mathrm{m}^{2}$ (fig 5 ).

In subgroup 3 mean right atrial pressure increased from $10.3(0.5)$ to $13.7(0.5) \mathrm{mm} \mathrm{Hg}$ $(\mathrm{p}<0.001)$, while neither right ventricular stroke work index $\left(5.0(2 \cdot 5) v 4 \cdot 7(2.3)\right.$ g.m.m ${ }^{-2}$, fig 4) nor stroke index $(40.1(14.5)$ v 38.3 $(8 \cdot 8) \mathrm{ml} /$ beat $/ \mathrm{m}^{2}$, fig 5$)$ changed significantly.

In subgroup 4 the increase in mean right atrial pressure from $11.4(1.3)$ to 16.7 $(1.4) \mathrm{mm} \mathrm{Hg}(\mathrm{p}<0.001)$ was accompanied by a significant reduction of right ventricular stroke work index from $5.0(2 \cdot 3)$ to 4.0 $(2 \cdot 5)$ g.m.m ${ }^{-2}(p=0.007$, fig 4$)$ and of stroke index from $38.4(13.1)$ to $34.7(13.5) \mathrm{ml} /$ beat $\mathrm{m}^{2}(\mathrm{p}=0.002$, fig 5$)$.

In subgroup 5 the reduction in mean right atrial pressure from $17.8(1.0)$ to 13.3 (1.9) $\mathrm{mm} \mathrm{Hg}(\mathrm{p}=0.002)$ produced by intravenous glyceryl trinitrate was followed by a significant increase in right ventricular stroke work index from $3 \cdot 8(2 \cdot 3)$ to $5 \cdot 1(2 \cdot 1)$ g.m.m ${ }^{-2}$ $(p=0.013$, fig 4$)$ and in stroke index from $39 \cdot 1$ (9.8) to $45.0(8.3) \mathrm{ml} /$ beat $/ \mathrm{m}^{2} \quad(\mathrm{p}<0.001$, fig 5).

The changes in cardiac index paralleled those for stroke index (fig 6).

\section{Discussion}

The filling pressure is a major determinant of ventricular performance in intact ${ }^{11-13}$ and diseased hearts. ${ }^{1415}$ This pressure is of critical importance in evaluating cardiac performance in patients with acute myocardial infarction. ${ }^{1-3}$ Haemodynamic, clinical, and experimental studies $^{1316}$ showed that the increase in filling pressure of the infarcted left ventricle up to the optimal level of 14-18 mm Hg in some studies ${ }^{3}$ and of $20-25 \mathrm{~mm} \mathrm{Hg}$ in others ${ }^{1}$ was followed by a parallel rise in cardiac output, stroke index, and left ventricular stroke work index. But data about the optimal filling pressure of the right ventricle in patients with right ventricular infarction are few and inconclusive. ${ }^{34}$

Some regarded as optimal mean right atrial pressures of $6-8 \mathrm{~mm} \mathrm{Hg},{ }^{3}$ but in their patients the real incidence of right ventricular infarction was unknown. For others the optimal value was $15.6 \mathrm{~mm} \mathrm{Hg},{ }^{4}$ but only in a subgroup of patients with cardiac index of $<2 \cdot 21 / \mathrm{min} / \mathrm{m}^{2}$. The range of haemodynamic function in patients with right ventricular infarction is much wider.

When we plotted ventricular function curves for right ventricular stroke work index (as a more specific indicator of the function of this ventricle) against mean right atrial pressure (fig 1) we found that an increase of mean right atrial pressure up to $10-14 \mathrm{~mm} \mathrm{Hg}$ was almost always followed by a rise in right ventricular stroke work index, whereas increases in mean right atrial pressure to above these values resulted in a level or even descending line. When mean right atrial pressure returned to 10-14 $\mathrm{mm} \mathrm{Hg}$ after treatment with glyceryl trinitrate right ventricular stroke work generally increased. The mean value of optimal right atrial pressure of the group, selected in each patient as the value of mean right atrial pressure corresponding to the highest right ventricular stroke work index, was found to be $11.7(2 \cdot 1) \mathrm{mm} \mathrm{Hg}$ (fig 2). This finding was supported by the analysis of pairs of points representing the relation between right ventricular stroke work index (and stroke index and cardiac index) and mean right atrial pressure that corresponded with the two different values of right atrial pressure produced by infusions of dextran or glyceryl trinitrate (figs 4-6). This analysis showed that the right ventricular stroke work index increased only in 
subgroups 1 and 5 . In subgroup 1 , the rise of mean right atrial pressure from $6.5(2 \cdot 1)$ to 11.5 $(1.7) \mathrm{mm} \mathrm{Hg}$ was followed by a considerable increase in right ventricular stroke work index and stroke index. In subgroup 5, too, right ventricular stroke work index and stroke index increased significantly when mean right atrial pressure was reduced from $17.8(1.0)$ to 13.3 (1.9) $\mathrm{mm} \mathrm{Hg}$ by infusion of glyceryl trinitrate.

The improvement in right ventricular performance at optimal filling pressure is a result of the stretching to their optimal length of the myocardial fibres that have survived necrosis; this, according to Starling's law, increases their contraction.

In subgroup 4, an increase in mean right atrial pressure from $11.4(1.3)$ to 16.7 $(1.4) \mathrm{mm} \mathrm{Hg}$ led to a significant decrease in the performance of the right ventricle. Others, too, have reported no improvement in right ventricular performance in patients with predominant right ventricular infarction when right atrial pressure is abnormally raised. ${ }^{17}$ The increase of right ventricular filling pressure above the optimal values reduces right ventricular performance because it augments the wall stress and the rigidity of the thin-walled right ventricle and affects left ventricular geometry ${ }^{18-20}$ and interventricular septal motion. ${ }^{192122}$ For these changes that derive from ventricular interdependence the intact pericardium will also have constrictive effects on the dilated heart. ${ }^{23-25}$

We found that the optimal pulmonary capillary pressure was $16 \cdot 8(2 \cdot 7) \mathrm{mm} \mathrm{Hg}$ (fig 3 ), nearly the same as that found in patients with left ventricular infarction. ${ }^{3}$ In 16 patients, however, the left ventricular function curves took the opposite course to those of the right ventricle. Others too have described patients in shock owing to right ventricular infarction who showed values of left ventricular filling pressure within optimal limits. ${ }^{26}$ These data clearly indicate that to maintain adequate cardiac performance in patients with biventricular infarction, both the left and right ventricular filling pressures need to be optimal.

Our study showed that the control of right ventricular filling pressure in patients with biventricular infarction enables the regulation to some degree of right ventricular performance according to Starling's law. Cardiac and stroke index increased and the right ventricle reached its maximum stroke work index when the filling pressure was $10-14 \mathrm{~mm} \mathrm{Hg}$. These values could, therefore, be considered as the optimal value of right ventricular filling pressure in patients with right ventricular infarction, though there were individual variations. 1 Rackley CE, Russell RO. Right ventricular function in acute

2 Forrester JS, Diamond G, McHugh TJ, Swan HJC. Filling pressures in the right and left sides of the heart in acute myocardial infarction. N Engl J Med 1971;285:190-3.

3 Crexells C, Chatterjee K, Forrester JS, Dikshit K, Swa HJC. Optimal level of filling pressure in the left side of the heart in acute myocardial infarction. $N \mathrm{Engl} \mathrm{J} \mathrm{Med}$ 1973;289:1263-6.

4 Coma-Canella I, Lopez-Sendon J, Adanez JV. Volume loading in patients with ischemic right ventricular dysfunction. Eur Heart $J$ 1981;2:329-39.

5 Lopez-Sendon J, Coma-Canella I, Gamallo C. Sensitivity and specificity of hemodynamic criteria in the diagnosis of acute right ventricular infarction. Circulation 1981; 64:515-24.

6 Daubert JC, Langella B, Besson C, Bourdonnec C, Pony JC Gouffault J. Etude prospective des critères diagnostiques et pronostiques de l'atteinte ventriculaire droite à la phase aiguë des infarctus inféro-posterieurs. Arch Mal Coeur 1983;76:991-1003.

7 Candell-Riera J, Figueras J, Valle V, et al. Right ventricula infarction. Relationships between ST segment elevation in $V_{4} R$ and hemodynamic, scintigraphic, and echocar diographic findings in patients with acute inferior myocardial infarction. Am J Cardiol 1981;101:281-7.

8 Edwards D, Whittaker S, Prior A. Cardiogenic shock without a critically raised left ventricular end diastolic pressure: management and outcome in eighteen patients. Br Heart $J$ 1986;55:549-53.

9 Mantle JA, Russell ROJ, Moraski RE, Rackley CE. Isosorbide dinitrate for the relief of severe heart failure after myocardial infarction. Am J Cardiol 1976;37:266-8.

10 Weiner BH, Alpert JS, Dalen JE, Ockene IS. Response of the right ventricle to exercise in patients with chronic heart the right ventricle to exercise in patients

11 Parker JO, Case RB. Normal left ventricular function. Circulation 1979;60:4-10.

12 Nixon JV, Murray GR, Leonard PD, Mitchell JH, Blomquist GC. Effect of large variations in preload on lef ventricular performance characteristics in normal subjects. Circulation 1982;65:698-703.

13 Glower DD, Tyson GS, Spratt JA, Walfe JA, Newton JR Rankin JS. Linearity of the Frank-Starling relationship in the intact heart [Abstract]. Circulation 1983;68 (supp III):III-1484.

14 Broder MI, Cohn JN. Evolution of abnormalities in left ventricular function after acute myocardial infarction. Circulation 1972;46:731-43.

15 Rahimtoola SH. Hemodynamics in myocardial infarction. Am J Cardiol 1974;33:691.

16 Bogen DK, Rabinowitz SA, Needleman A, McMahon TA Abelmann WH. An analysis of the mechanical disadvantage of myocardial infarction in the canine left ventricle. tage of myocardial infarction

17 Dell'Italia LJ, Starling MR, Blumhardt R, Lasher JC O'Rourke A. Comparative effects of volume loading, dobutamine and nitroprusside in patients with predomin ant right ventricular infarction. Circulation 1985;72: $1327-35$

18 Goto Y, Yamamoto J, Saito $\mathrm{M}$, et al. Effects of righ ventricular ischemia on left ventricular geometry and the end diastolic pressure-volume relationship in the dog. Circulation 1985;72:1104-14.

19 Sharkey S, Shelly W, Rusavy J, Cohn JN. Ventricula interaction in right ventricular infarction. The role of the septum [Abstract]. Circulation 1983;68 (suppl III):III1484.

20 Visner MS, Arentzen CE, O'Connor MJ, Larson EV, Anderson RW. Alterations in left ventricular threedimensional dynamic geometry and systolic function during acute right ventricular hypertension in the conscious dog. Circulation 1983;67:353-65.

21 Mikell FL, Asinger RW, Hodges M. Functional consequences of interventricular septal involvement in right vences of interventricular septal involvement in right ventricular infarction. Echocardiographic clinical and 393-401.

22 Kingma I, Tyberg JV, Smith ER. Effects of diastolic transseptal pressure gradient on ventricular septal position and motion. Circulation 1983;68:1304-14.

23 Refsum H, Jünemann M, Lipton MJ, Skioldebrand C Carlsson E, Tyberg JV. Ventricular diastolic pressurevolume relations and the pericardium. Circulation 1981 64:997-1004.

24 Goldstein JA, Vlahakes GJ, Verrier ED, et al. The role of right ventricular systolic dysfunction and elevated intrapericardial pressure in the genesis of low output in experimental right ventricular infarction. Circulation 1982;65:513-22.

25 Smiseth OA, Scott-Douglas NW, Thompson CR, Smith ER, Tyberg JV. Non-uniformity of pericardial surface pressure in dogs. Circulation 1987;75:1229-36.

26 Cohn JN, Guiha NH, Broder MI, Limas CJ. Right ven tricular infarction. Clinical and hemodynamic features. Am J Cardiol 1974;33:209-14. 